\title{
Application of a sub-specialties management model improves quality control in a central sterile supply department
}

\author{
Li Wang ${ }^{\dagger}$, Xuejiao Cai ${ }^{\dagger}$ and Ping Cheng ${ }^{*}$
}

\begin{abstract}
Background: The management of medical devices is crucial to safe, high-quality surgical care, but has received little attention in the medical literature. This study explored the effect of a sub-specialties management model in the Central Sterile Supply Department (CSSD).

Methods: A traditional routine management model (control) was applied from September 2015 through April 2016, and a newly developed sub-specialties management model (observation) was applied from July 2016 through February 2017. Health personnel from various clinical departments were randomly selected to participate as the control $(n=86)$ and observation $(n=90)$ groups, respectively. The groups were compared for rates of personnel satisfaction, complaints regarding device errors, and damage of medical devices.

Results: The satisfaction score of the observation group ( $95.8 \pm 1.2)$ was significantly higher than that of the control $(90.2 \pm 2.3 ; P=0.000)$. The rate of complaints of the observation group (3.3\%) was significantly lower than that of the control $(11.6 \% ; P=0.035)$. The quality control regarding recycle and packing was significantly higher during the observation period than the control period, which favorably influenced the scores for satisfaction. The rate of damage to specialist medical devices during the observation period (0.40\%) was lower than during the control period (0.61\%; $P=0.003)$. The theoretical knowledge and practical skills of the CSSD professionals improved after application of the sub-specialties management model.
\end{abstract}

Conclusions: A management model that considers the requirements of specialist medical devices can improve quality control in the CSSD.

Keywords: Sub-specialties, Central sterile supply department, Quality control, Medical device

\section{Background}

The central sterile supply department (CSSD) of a health care facility provides sterilized materials to wards, operating rooms, transplant units, and outpatient departments. The CSSD is located in the hospital and is responsible for the recycling, cleaning, sterilization, inspection, packaging, and delivery of all medical devices to various users in the hospital [1]. The reliability of sterile supplies from the CSSD

\footnotetext{
* Correspondence: chengping197307@suda.edu.cn

${ }^{\dagger}$ Li Wang and Xuejiao Cai contributed equally to this work.

Central Sterile Supply Department, First Affiliated Hospital of Soochow

University, Suzhou City 215008, Jiangsu Province, China
}

greatly depends on the quality control of the sterilization process. Indeed, good sterilization and packaging practices provided by the CSSD directly influence the quality of health care [2], and more importantly, patients' safety $[2,3]$. Therefore, it is of utmost importance to ensure the quality control of the sterilization process. However, with technological improvements in medical care, the medical devices used in clinics have become more complicated and specialized. Mishandling of these advanced medical devices by the CSSD can lead to damage and poor sterilization. This is considered a challenge in the CSSD.

With time the practice of medicine has become divided into various and refined sub-specialties [4] reflected by 
clinical departments such as anesthesia [5, 6], pathology [7], and burns [8]. However, there has been no concomitant specialization within the CSSD for providing services to these clinics. The traditional management model of the CSSD is no longer satisfactory, and recent studies of CSSD management methods have shown limited improvements in quality control [9]. Establishing a management model for the CSSD that considers the needs of the sub-specialty clinics would be helpful to adapt services to meet these challenges more appropriately [10]. However, to our best knowledge, no previous study has evaluated the role of a sub-specialties management model as it influences quality control in the CSSD.

The present study investigated the effect of a sub-specialties management model on quality control and health professional's satisfaction within the CSSD.

\section{Methods}

\section{Study design and study participants}

This is a retrospective study comparing 2 management models in our hospital. A traditional routine management model (described below) was applied in our hospital from September 2015 through April 2016, and this was set as the control treatment. In contrast, the observation management model was applied based on a sub-specialties management model that was implemented from July 2016 through February 2017. A specialist device was defined as a device used by one specific clinical department. The study participants comprised healthcare personnel that were randomly selected from the following departments: operating room, stomatology, gynecology, orthopedics, thoracic surgery, urinary surgery, and general surgery.

A total of 92 staff members were randomly selected to constitute the control group, and 100 staff members were randomly selected for the observation group. Questionnaires were sent to the control group in May 2016 and to the observation group in March 2017. Questionnaires were designed based on relevant studies in the literature with some revisions made by our center $[11,12]$. All recruited staff members during the control and observation periods were invited to answer our questionnaire.

The questionnaire was a modified version based on previous work by Shan et al. [13] with good reliability and validity (Cronbach $\alpha=0.978$; validity $=0.963$ ). The questionnaire mainly consisted of 3 domains (recycling, packaging, and sterilization) including 21 items, in which participants scored their satisfaction regarding the services provided by the CSSD during the previous 6 months. For the satisfaction survey, participants were asked to reply by selecting one rating from five categories, ranging from 'Strongly satisfied' to 'Strongly dissatisfied'. The answer 'Strongly satisfied' was assigned a score of 5 points, while 'Strongly dissatisfied' was assigned a score of 1 . The satisfaction score was the sum of these scores. The questionnaire also collected data regarding participants' general information (age, gender, clinical department, highest education level, and professional title). In our hospital, all professionals were classified into 3 groups according to their professional level: low, medium, or high.

We also conducted tests of knowledge and skills among the professional staff $(n=27)$ on March 2016 and January 2017 during the control and observations periods, respectively, in the CSSD.

\section{Management models \\ Control treatment}

For the control treatment (routine management), the CSSD consisted of 3 working zones: cleaning; sterilization and packaging; and sterile storage. A team leader was assigned to each zone, who assisted the head supervisor of the CSSD to complete all the work of the zone. The working professionals in the CSSD were randomly assigned to the different working zones.

\section{Observation treatment}

The observation treatment (i.e., sub-specialty management model) supplemented the traditional model with various modules to improve quality control. Based on the results of a medical device-related scale evaluation, in the CSSD specialist medical devices were classified into 3 sub-specialties: laparoscopic; stomatology; or rental. Staff personnel in the CSSD were assigned to the different sub-specialty groups based on their professional title, working years in the CSSD, highest educational level, working ability, and personal willingness.

Each sub-specialty group took full responsibility for the cleaning, disinfection, sterilization, and packaging of medical devices within that sub-specialty. The CSSD professionals in each group worked closely with the relevant clinical departments. Clinicians in the relevant departments were regularly invited to deliver speeches on the clinical use and maintenance of specific medical devices. All the sub-specialty group members worked in the cleaning zone, and the sterilization and packaging zone. Shifts between different sub-specialty groups took place every 6-12 months.

\section{Statistical analysis}

Sample size was calculated based on $\alpha=5 \%$ and $\beta=90 \%$. An increase of $\geq 10$ points of satisfaction score was defined as clinical improvement; the expected sample was $\geq 81$. In consideration of a possible $10 \%$ non-response rate, we determined that an invitation letter should be sent to $\geq 90$ participants.

The t-test was used to compare age, satisfaction scores, complaint rate, device damage rate, skill scores, and error rate. The chi-squared test $\left(\mathrm{x}^{2}\right)$ was applied to 
compare education and professional levels. A 2-sided $P$-value $<0.05$ was considered statistically significant. All analyses were conducted using the SPSS 17.0 software (SPSS, Chicago, IL, USA).

\section{Results}

We received 86 questionnaires (response rate 93.5\%) during the control period, and 90 questionnaires (response rate 90\%) during the observation period. The distributions of age, gender ratio, education level, and professional title were similar between the 2 groups (Table 1). The average age of the control and observation groups was $35.9 \pm 7.8$ years and $37.2 \pm 9.0$ years, respectively.

Compared with the control group, the observation group had significantly lower complaint scores (Table 2). The overall satisfaction score of the observation group $(95.8 \pm 1.2)$ was significantly higher than that of the control group $(90.2 \pm 2.3 ; P=0.000)$. The quality of recycled devices reported by the observation group $(32.8 \pm 4.5)$ was significantly higher than that of the control group $(30.2 \pm 4.2 ; P=0.000)$. Furthermore, the quality of device packing reported by the observation group $(32.4 \pm 4.2)$ was significantly higher than that of the control group $(30.9 \pm 3.6 ; P=0.01)$. The sterilization quality of devices reported by the 2 groups was comparable $(P=0.131)$.

In the control group, 44,652 pieces of medical devices were cleaned and sterilized. Of these, 21,780 pieces were specialist medical devices, among which 132 (0.61\%) were damaged in the CSSD (Table 3). During the observation period, 50,445 pieces of medical devices were cleaned and sterilized. Of these, 22,044 were specialist medical devices, among which $89(0.40 \%)$ were damaged in the CSSD. Thus, the damage rate of specialist medical devices during the observation period $(0.40 \%)$ was significantly lower in that of the control period $(0.61 \%$; $P=0.003)$.

Significant improvement was also observed during the observation period regarding the professional skills of the CSSD workers, of which both theoretical knowledge and practical skills were evaluated. The theoretical knowledge score of the observation group $(93.7 \pm 5.0)$ was significantly higher than that of the control $(87.3 \pm$ 5.5; $P=0.002$; Table 3). The scores for practical skills of the CSSD professionals during the observation period $(91.6 \pm 5.1)$ were significantly higher than during the control period $(86.4 \pm 4.7 ; P=0.009)$. The medical device damage rate was significantly higher in the control group than the observation group.

\section{Discussion}

The current study explored the application of a sub-specialties management model that can ensure good sterilization practices in the CSSD. We developed sub-specialty modules that were based on clinical need, with specified management for various medical devices. Our study indicates that the application of a management model that considered sub-specialties in the CSSD increased the satisfaction of the clinical healthcare staff, decreased the number of complaints, and lowered rates of medical device damage and error. These improvements are partly due to the enhanced theoretical knowledge and practical skills of the CSSD professionals.

Previous studies have also explored potential methods to improve control of safety in the CSSD. Debabrata et al. [10] reported that retaining sterilization records was helpful to ensure high safety control, as recordkeeping facilitated monitoring the quality of daily work practices. In China and some other countries, hospitals have increasingly applied an instrument tracking system in the CSSD, which has reduced the risk of errors in packaging surgical instruments, including missing and mismatched instruments $[14,15]$.

The physical infrastructure of the CSSD consists of separate work areas for decontamination, packaging, linen preparation, and sterile storage. Clear job assignments are highly important in the CSSD layout of these areas. In the present study, the designed management

Table 1 Baseline characteristics of the study population

\begin{tabular}{|c|c|c|c|c|c|}
\hline & & Control & Observation & Test value & $P$ \\
\hline Subjects, n & & 86 & 90 & & \\
\hline Age, y & & $35.9 \pm 7.8$ & $37.2 \pm 9.0$ & $t=1.049$ & 0.296 \\
\hline \multirow[t]{2}{*}{ Gender } & Male & $40(46.5 \%)$ & 38 (42.2\%) & $x 2=0.328$ & 0.567 \\
\hline & Female & 46 & 52 & & \\
\hline \multirow[t]{3}{*}{ Education level } & Associate's & 19 & 22 & $x^{2}=0.327$ & 0.849 \\
\hline & Bachelor's & 30 & 33 & & \\
\hline & Master's or above & 37 & 35 & & \\
\hline \multirow[t]{3}{*}{ Professional title } & Low & 13 & 14 & $x 2=0.152$ & 0.927 \\
\hline & Medium & 33 & 32 & & \\
\hline & High & 40 & 44 & & \\
\hline
\end{tabular}


Table 2 Degree of satisfaction and complaint rate between control and observation groups

\begin{tabular}{|c|c|c|c|c|c|}
\hline & & Control & Observation & Test value & $P$ \\
\hline Subjects, $n$ & & 86 & 90 & & \\
\hline \multirow[t]{4}{*}{ Satisfaction scores } & & $90.2 \pm 2.3$ & $95.8 \pm 1.2$ & $t=19.80$ & 0.000 \\
\hline & Recycle quality & $30.2 \pm 4.2$ & $32.8 \pm 4.5$ & $t=4.00$ & 0.000 \\
\hline & Packing quality & $30.9 \pm 3.6$ & $32.4 \pm 4.2$ & $t=2.59$ & 0.010 \\
\hline & Sterilization quality & $29.2 \pm 6.1$ & $30.6 \pm 6.3$ & $t=1.52$ & 0.131 \\
\hline Complaint rate & & $11.6 \%$ & $3.3 \%$ & $x 2=4.42$ & 0.035 \\
\hline
\end{tabular}

model specified a job assignment with experienced personnel for each working module. This subsequently reduced the error rate of the entire process.

A previous study identified job assignment as an important indicator of the performance of CSSD quality control [16]. The study also suggested that CSSD personnel require continuing professional development through education, otherwise they will not be able keep up with advancements in the technology of new machines. Continuing professional development is a component of our management model, whereby CSSD professionals receive knowledge and training regarding the clinical use of medical devices. In the present study, the training program designed for the packaging staff in the CSSD was shown to be helpful for improving their knowledge of equipment. Staying educated in the CSSD is not easy, but is necessary for providing effective and efficient service [17].

The CSSD is often a neglected area of infection control in hospitals. Investment in a well-equipped CSSD infrastructure is essential for the smooth functioning of a hospital. Resources should be directed not only for the development of the physical infrastructure and equipment in the CSSD, but also for the recruitment and retention of technically qualified personnel who are able to operate the system effectively [18].

In the present study, it should be noted that the clinics' satisfaction score for sterilization remained unchanged after application of the sub-specialty model. Quality control of the sterilization process is complex. A previous study suggested that quality assurance for sterilization can depend on several factors, including compliance with sterilization guidelines, validation of sterilization instruments, the use of chemical and biological indicators, and precautions against sharp injury [16]. The Association for the Advancement of Medical Instrumentation and the
International Standards Organization has provided recommendations regarding physical parameters and chemical and biological indicators that ensure sterilization quality control. Debabrata et al. [19] shared their experience with the application of various sterilization indicators in the CSSD of a 167-bed oncology hospital in eastern India.

Errors in instrument processing can increase operative time and costs, and can potentially contribute to surgical infections and perioperative mortality [20,21].

Our present study found that the rate of reported errors was significantly lower during the observation period than during the control period. It has been reported that $44.0 \%$ of errors in a Chinese hospital occurred because of errors in the labeling of packed instruments, and mainly among instruments of similar type (currently in manuscript). Instruments of similar structure are frequently mixed, and this is usually due to personnel error. Hospital personnel working in the CSSD are unfamiliar with the application of surgical instruments in clinics, which increases their difficulties in distinguishing between instruments with minor differences. In the present study, the continuous training provided by our management model successfully increased the knowledge and skills of the CSSD professionals. This was probably responsible for the subsequent reduction in errors during the sterilization or packaging processes.

The error rate may furthermore be reduced by using the Lean method [22], which improves the processing of surgical instruments by redefining operator roles, altering the workplace, mistake-proofing, quality monitoring, staff training, and continuous feedback. The Virginia Mason Medical Center in Seattle, WA, improved the process of surgical instrument sterilization by applying Lean production improvement methods, and entitled this the Virginia Mason Production System [22]. Instrument processing errors decreased from 3.0 to $1.5 \%$, in

Table 3 Evaluation of CSSD professionals' theoretical knowledge, and practical skills, and error rate during work

\begin{tabular}{lllll}
\hline & Control & Observation & Test value & $P$-value \\
\hline Theoretical knowledge & $87.3 \pm 5.5$ & $93.7 \pm 5.0$ & $t=3.40$ & 0.002 \\
Practical skill & $86.4 \pm 4.7$ & $91.6 \pm 5.1$ & $t=2.88$ & 0.009 \\
Error rate & $0.92 \%(409 / 44652)$ & $0.52 \%(263 / 50445)$ & $X 2=52.57$ & 0.000 \\
Device damage & $0.61 \%(132 / 21780)$ & $0.40 \%(89 / 22044)$ & $X 2=8.94$ & 0.003 \\
\hline
\end{tabular}


particular assembly errors in packaging (from 0.66 to 0.24 errors per 100 cases).

\section{Conclusion}

The current study demonstrated the beneficial effects of instituting the sub-specialty management model for quality control of medical devices in the CSSD.

\section{Abbreviations}

AAMI: Advancement of Medical Instrumentation; CSSD: Central Sterile Supply Department; ISO: International Standards Organization; VMPS: Virginia Mason Production System

\section{Acknowledgements}

I thank Profess Yulun Huang. In the process of composing this paper, he gave me much academic and constructive advice, and helped me with corrections.

\section{Funding}

This study was supported by the Health and Family Planning Commission of Jiangsu Province Youth Research Subject (No. Q201606), the Six Talent Peaks Project in Jiangsu Province (No. 2014-wsw-021), and the Suzhou Applied Basic Research (No. Sys201535).

\section{Availability of data and materials}

The datasets that were used or analyzed during the current study are available from the corresponding author on reasonable request.

\section{Authors' contributions}

LW and CX collected and analyzed the data regarding satisfaction scores. PC was a major contributor in writing the manuscript. All authors read and approved the final manuscript.

\section{Ethics approval and consent to participate}

The scope of review of the ethics committee concerns only people involved in biomedical research and related technology applications. Our study explored the effect of a sub-specialties management model in the Central Sterile Supply Department. Rates of personnel satisfaction, complaints regarding device errors, and damage of medical devices were compared between 2 models. This study only involves management, and not any sterilization or package method. Our ethics committee ruled that no formal ethics approval was required for this study.

\section{Competing interests}

The authors declare that they have no competing interests.

\section{Publisher's Note}

Springer Nature remains neutral with regard to jurisdictional claims in published maps and institutional affiliations.

Received: 2 January 2018 Accepted: 17 May 2018

Published online: 30 May 2018

\section{References}

1. National Health and Family Planning Commission of the People's Republic of China. Management standard in central sterile supply department of hospital. Available via: 2016-12-27. Accessed at http://www.moh.gov.cn/ zhuz/s9496/201701/bbf3172246bd4fc49d4562a66407dd99.shtml.

2. Rosenbaum BP. Radio frequency identification (RFID) in health care: privacy and security concerns limiting adoption. J Med Syst. 2014;38:19.

3. Suying W. Nursing department's experiences in reestablishment of central sterile supply department. Chin Nurs Manag. 2009;9:66-7.

4. Lan C, et al. Training programs for nurses in critical severe sub-specialties. Nurs J Chin Peoples Liberation Army. 2013;9:66-7.

5. Yu J, Zuo Y, Liu J. Observation study on the establishment of anesthesiology sub-specialty in tertiary level hospital. Int J Anesth Resus. 2015;6:573-6

6. Jiangqin L, Yong L, Chunmei C. The effect of nuring sub-specialties establishement on nuring quality in operation room. World Latest Med Inform. 2014;15:42
7. Hua $F$, et al. Experience of training sub-speciality pathologist. Med Inf. 2014;18:17.

8. Wen L, et al. Specialty nurse training in burns department. Mod Med Health 2012;28:1418-20.

9. Veiga-Malta I. Preventing healthcare-associated infections by monitoring the cleanliness of medical devices and other critical points in a sterilization service. Biomed Instrum Technol. 2014;50:45-52.

10. Basu D, et al. The importance of paper records and their preservation period in a central sterile supply department: an experience from a oncology center in eastern India. J Infect Public Health. 2017;10:685-7.

11. Jiao M. Satisfaction survey and strategy analysis in clinical department toward Central Sterile Supply Department. Journal of Clinical Medical Literature. 2016:3:10451.

12. Wang F. Countermeasures and analysis of the satisfaction survey of clinical departments on disinfection supply room. Chinese Community Doctors. 2014;7:175-6.

13. Shan $\mathrm{H}$, et al. Reliability and validity evaluation of performance appraisal satisfaction questionnaire on medical staff in a class III grade I hospital. Chin Nurs Res. 2017;31:947-50.

14. Duro M. Surgical instrument tracking system advancements and benefits. AORN J. 2014;100:C7-8.

15. Azizi J, et al. Uphill grime: process improvement in surgical instrument cleaning. AORN J. 2012;96:152-62

16. Sangthong $\mathrm{K}$, et al. Development of quality indicators for sterilization practices of the central sterile supply department. J Med Assoc Thail. 2005; 88:5128-32.

17. Colacci J. Key strategies to help central sterile supply department professionals promote state certification. AORN J. 2011:94:618-20.

18. Basu $D$, et al. The importance of the central sterile supply department in infection prevention and control. Infect Control Hosp Epidemiol. 2014;35: 1312-4.

19. Basu D, et al. Reason behind wet pack after steam sterilization and its consequences: an overview from central sterile supply department of a cancer center in eastern India. J Infect Public Health. 2017;10:235-9.

20. Khan SA, et al. Accidentally falling instruments during orthopaedic surgery: time to wake up. ANZ J Surg. 2008;78:794-5.

21. Wong J, et al. Delays in the operating room: signs of an imperfect system. Can J Surg. 2010;53:189-95.

22. Blackmore CC, Bishop R, Luker S, Williams BL. Applying lean methods to improve quality and safety in surgical sterile instrument processing. Jt Comm J Qual Patient Saf. 2013:39:99-105.

\section{Ready to submit your research? Choose BMC and benefit from}

- fast, convenient online submission

- thorough peer review by experienced researchers in your field

- rapid publication on acceptance

- support for research data, including large and complex data types

- gold Open Access which fosters wider collaboration and increased citations

- maximum visibility for your research: over $100 \mathrm{M}$ website views per year

At BMC, research is always in progress.

Learn more biomedcentral.com/submissions 